\title{
Daniel Forthomme, optometrist, professor, researcher, director and friend (1938-2019)
}

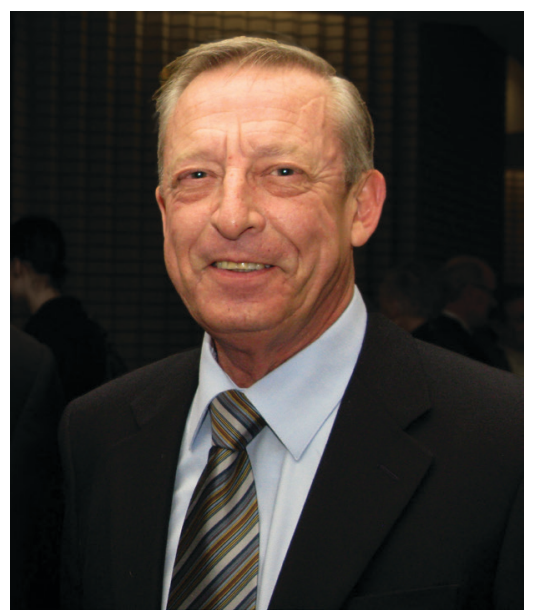

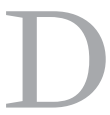
aniel Forthomme had a profound influence on many of us and on our profession. Throughout his long career as an optometrist, professor, director of the School of Optometry and of Optométristes Sans Frontières, he adapted to change, always giving his best; hence his remarkable influence on all Quebec optometrists and on our profession.

A gracious and kind man, he had an exquisite sense of humour, finesse and great elegance. Born in Koersel, Belgium, he attended Collège St-Servais in Liège during his teens, and then trained as an optician at the Institut d'Optique Raymond-Thibault in Brussels. Too shortsighted to fulfil his dream of becoming an airplane pilot, he did achieve his dream of settling in Canada. In 1963, he earned an optometry license from the Université de Montréal. Daniel began his teaching career in the mid1960 s as a laboratory assistant. He made contact lenses, his chosen field. In 1969, the School of Optometry, which as formerly affiliated, became integrated into the Université de Montréal, and Daniel was hired as an "assistant professor". He was granted professional development leave, which he spent in the Department of Pathology, Faculty of Medicine, where he earned a Master's degree in 1973. His Master's thesis described the retinal vascular network and the renal glomerulus during experimental heart failure. After earning his Master's degree, he pursued doctoral studies and then returned to teaching and the clinic in 1975. During his Ph.D., which he completed in 1980, Daniel described the retinal vascular network in experimental hypertension in rats. His innovative research on experimental hypertension and the retina was conducted in cooperation with Dr. Marc Cantin, a specialist in hypertension and atrial natriuretic factor (ANF) at the Montreal Clinical Research Institute.
Daniel trained generations of optometrists in the contact lens industry, not only by giving courses in theory, but also through clinical teaching, until he retired from the Université de Montréal. His advanced training in histology enabled him to link cellular disruptions with macroscopic changes observable with a slit lamp. He was also a master with the bio-microscope, which he systematically used right from the beginning of his practice. What a pleasure it was to hear his observations of the patient's eye when he would be operating his Zeiss photographic bio-microscope in order to enter those observations into the record. While watching closely through the observation tube, we envied his knowledge and his marvellous way of expressing it.

Daniel initiated multiple students who had chosen to expand their contact lens knowledge, through various procedures used in that field. That was true of slit lamp photography. That was another of Dr. Forthomme's legacies to optometry because, by training young optometrists interested in documenting their clinical cases using this approach, he helped expand the popularity of photo-documenting clinical cases in practice, not just with a bio-microscope, but also with other devices. He also introduced a number of students to the optical measuring of corneal thickness which, at the time, was reserved for research activities. That method was very arduous: it required adjusting to the darkness and, in the bio-microscope, aligning the rear surface of an optical cut of the cornea seen in an upper hemifield with the front surface of that cut seen in the other hemifield. After calibration, the corneal thickness measurement was obtained. Under his direction during a Master's degree, one of us (CG) noticed how knowledgeable Daniel was about the literature on optical pachymetry. That tech- 
nique was widely used in many studies on the effect of contact lenses in Kenneth Polse's laboratory because, at the time, it was the only non-invasive technique. It had the advantage of being able to assess corneal edema without touching the cornea, which proved useful in studies where the subject had to keep wearing his/her contact lenses. There are now several simpler and more easily repeatable methods for measuring corneal thickness. They are very often used in clinics today because assessing corneal thickness provides information about the risk of developing glaucoma. This is another of Daniel's contributions to eye examinations.

Daniel was also a pioneer by expanding the breadth of optometrists' general education. That was long before the undergraduate optometry program offered a strong component in biomedical science. It was with him as director of the School of Optometry from 1985 to 1989 that the university and the profession understood the importance of investing in their school. That enabled his successor to have much greater means for developing the school's research activities and improving its clinical programs. With Daniel at the helm, the OD program intended for practising optometrists was finalized. In addition, he agreed to have three of the young professors at the time, the authors of this article, go on career development leave in turn in order to earn a Ph.D. At the graduate level, Daniel was a model supervisor for a Master's student: a positive professor helping his protégé establish protocol and gain experience, using his wonderful writing to correct the first drafts of a student's literature review without backtracking on their topic, always willing to discuss the initial results, all without discouraging the student, but showing them the way. Following his term as Director of the School, he returned to teaching and clinical practice until he retired from the Université de Montréal in 1998. He then had the opportunity to achieve a variation on his dream, gliding, like his famous fellow-countryman, Jacques Brel. Also like him, Daniel began to go to small aerodromes throughout the province ...

\section{A HUMANITARIAN LEGACY}

Starting in 1991, he arranged internships for optometry students, who accompanied him to disadvantaged areas in Central and South America. He had asked optometrists' offices to provide old frames and glasses that were no longer in use. [TRANSLATION] "After a good cleaning," he said, "we went mainly to South America with five or six students at a time and nearly 600 pairs of recycled frames. After our time there, women were able to start sewing again and shoemakers could start working again." In that way, he was one of the pioneers in the recovery of used glasses and the start-up of Optométristes Sans Frontières in 1998. Honduras, Haiti, the Philippines, Peru, Ecuador and Roumania are among the countries where he provided care, in addition to providing glasses to disadvantage people. ${ }^{1}$ In addition to the charitable act of being able to equip those people with recycled corrective eye wear; and those internships enabled the students to complete their training in identifying eye conditions. At that time, there were no optometrist training clinics in Quebec hospitals. We had to see optometry students return from those internships transformed and with a greater awareness of the hardship of others. Great friendships formed between Daniel and optometrists on mission during that work with those disadvantaged populations.

He also had some health problems for which he had to be brought back to Canada urgently. That didn’t prevent him from returning there or going to the far north to do examinations for under-serviced Indigenous populations. He recently shared the following anecdote in a humorous way: during a mission to a Cree village, he thought he heard the beeping signal of a truck backing up... it was actually the battery of his pacemaker that needed to be replaced right away! That's the kind of man he was: generous, simple and endearing. Daniel continued clinical activities in private practice, temporarily replacing a number of optometrists on maternity or sick leave and more permanently in Outremont, until 2018.

In addition to his frequent field assignments, he served until 2017 on the Board of Directors of OSF (Optométristes Sans Frontières) which was able to benefit from his extensive experience. The Association des Optométristes du Québec and the Ordre des Optométristes du Québec presented him with awards, including the Award of Merit from the Québec Interprofessional Council for his contribution to underprivileged populations. Several years ago, the School of Optometry recognized him as one of the builders of optometry in Quebec.

On December 9, his sons Yves and Éric along with many colleagues and friends gathered at the Centre Funéraire Côte-des-Neiges to say good-bye to him. After representatives of his colleagues and his sons had the chance to speak, the ceremony ended, at his request, with Brel's song, "Adieu l'Émile,", in which the words [TRANSLATION] "I want people to laugh, I want people to sing when they put me in the hole," perfectly reflect Daniel's good humour. His wonderful human qualities, his sense of humour, his teasing and his friendship will be missed by everyone who had the opportunity to know him well. We have lost a friend. Quebec optometry has lost a giant. •

\section{Claude Giasson, Jacques Gresset et Pierre Simonet}

